\title{
A New Role for Complement in Experimental Membranous Nephropathy in Rats
}

\author{
David J. Salant, Steele Belok, Michael P. Madaio, and William G. Couser, \\ Evans Memorial Department of Clinical Research and Department of \\ Medicine, University Hospital, Boston University Medical Center, \\ Boston, Massachusetts 02118
}

\begin{abstract}
A в S T R A C T The only established role for complement in mediating immunologic renal disease involves elaboration of leukochemotactic factors and neutrophildependent glomerular injury. In the passive Heymann nephritis (PHN) model of experimental membranous nephropathy, rats injected with sheep antibody to rat proximal tubular brush border antigen ( $\mathrm{F} \times 1 \mathrm{~A})$ form subepithelial deposits of sheep IgG and rat complement (C3), and develop heavy proteinuria after $5 \mathrm{~d}$ without glomerular inflammatory changes. To study the role of complement in mediating proteinuria in $\mathrm{PHN}$, 16 rats were treated daily with cobra venom factor from before antibody injection to maintain C3 levels at $<10 \%$ of pretreatment values and compared to 16 untreated controls. Proteinuria at $5 \mathrm{~d}$ was abolished in C3-depleted rats $(4 \pm 1$, controls $70 \pm 15 \mathrm{mg} / \mathrm{d}, P$ $<0.001$ ), although renal deposition of ${ }^{125}$ I-labeled antibody was the same in both groups $(188 \pm 35$ vs. $191 \pm 22 \mu \mathrm{g}$ IgG/2 kidneys, $P>0.5$ ). Nephritogenic doses of both the noncomplement-fixing $\mathrm{F}\left(\mathrm{ab}^{\prime}\right)_{2}$ portion and the $\gamma 2$ subclass of anti-FxlA IgG produced subepithelial deposits of immunoglobulin without C3, but proteinuria did not occur despite glomerular deposition of up to $70 \mu \mathrm{g} / 2$ kidneys of $\gamma 2$. However, glomerular deposition of as little as $60 \mu \mathrm{g}$ of $\gamma \mathrm{l}$ produced C3 fixation in vivo and heavy proteinuria. No neutrophil exudate could be detected histologically in PHN from the time of antibody injection through
\end{abstract}

Portions of this work were presented at the 35th annual meeting of the American Federation for Clinical Research, San Francisco, California, 30 April 1978, and at the eleventh annual meeting of the American Society of Nephrology, New Orleans, La., 20 November 1978 and have been published in abstract form in 1978. (Clin. Res. 26: 384. Kidney Int. 14: 717.)

Dr. Salant is the recipient of a National Institutes of Health Clinical Investigator Award (AM 00742). Dr. Couser is the recipient of a National Institutes of Health Research Career Development Award (AM 00102). Address reprint requests to Dr. Couser.

Received for publication 17 March 1980 and in revised form 4 August 1980. development of proteinuria. Proteinuria in five PHN rats depleted of neutrophils to $<200 / \mathrm{mm}^{3}$ with antineutrophil serum was not reduced compared to six controls with normal neutrophil counts $(34 \pm 9.6$ vs. $25 \pm 10.4 \mathrm{mg} / \mathrm{d}, P>0.5)$.

These results demonstrate that proteinuria in the PHN model of membranous nephropathy is complement-dependent and strongly suggest a neutrophilindependent mechanism. Thus a new role for the complement system in mediating immunologic glomerular injury is identified.

\section{INTRODUCTION}

Immunopathologic studies in experimental animals and in man have now firmly established that glomerular antibody deposition mediates most forms of glomerular injury (1). At least three different mechanisms have been identified that may lead to immune deposit formation in glomeruli: antibody may bind to antigenic components of the glomerular basement membrane $(\mathrm{GBM})^{1}(2)$; antibody complexed to either exogenous or endogenous antigens in the circulation may form soluble immune complexes that are passively trapped by the glomerular filter (2); or antigens that are either glomerular constituents or glomerular tissue-bound exogenous macromolecules may bind free antibody to initiate in situ glomerular immune complex formation (3). Regardless of which of these mechanisms is involved, it is generally accepted that the resultant tissue injury, which manifests primarily as an increase in urine protein excretion, is usually effected by various mediator systems that are activated by the immune deposits $(1,4,5)$. The best defined of these mediators is the complement system, components of which are

\footnotetext{
${ }^{1}$ Abbreviations used in this paper: CVF, cobra venom factor; Fx1A, proximal tubular epithelial cell brush border antigen; GBM, glomerular basement membrane; IF, immunofluorescence microscopy; PHN, passive Heymann nephritis.
} 
prominent in immune deposits in glomerulonephritis (6-8). Although certain anti-GBM antibodies may induce heavy proteinuria independently of the complement system $(5,9-11)$ most studies in nephrotoxic nephritis models have shown that the complement system plays an essential role in this process $(8,9$, $12-14)$. Further, it has been established that complement-dependent glomerular injury involves the influx of neutrophils and local inflammation induced by the leukochemotactic complement fragment C5a and can be prevented by neutrophil depletion $(4,5,8,9,15)$. Numerous other biologic activities of various products of complement activation have been identified but there is presently no direct evidence that complement mediates glomerular injury by any mechanism other than that involving neutrophils $(5,8,16)$.

We $(17,18)$ and others $(19)$ have recently studied the mechanisms of subepithelial immune deposit formation in the passive Heymann nephritis (PHN) model in rats, a model that closely resembles membranous nephropathy in man. These studies showed that deposits may form locally by binding of free antibodies to a fixed glomerular antigen rather than from circulating complex trapping as previously believed. Careful, sequential studies of the development of this lesion during the $5 \mathrm{~d}$ between antibody injection and appearance of proteinuria revealed that complement was a prominent early constituent of the subepithelial immune deposits, but that proteinuria occurred in the absence of any detectable neutrophil infiltrates $(17,18)$. These findings are similar to those in the related autologous immune complex nephropathy (Heymann nephritis) model and in membranous nephropathy in $\operatorname{man}(20,21)$. In the present report our studies of the role of complement and neutrophils in PHN are described in detail. The results strongly suggest a previously unrecognized role for the complement system that is independent of neutrophils in this unique form of glomerular injury. These findings may be important in understanding the pathogenesis of several noninflammatory glomerular diseases in which complement deposits are prominent.

\section{METHODS}

All studies were carried out during the heterologous phase of PHN induced in rats by a single intravenous injection of sheep antibody to rat proximal tubular brush border antigen $(\mathrm{Fx} 1 \mathrm{~A})$ as described in detail previously $(17,18,22)$. To clarify the studies performed, the experimental protocol is outlined first followed by the specific details of each procedure.

\section{Experimental design}

\section{ROLE OF AUTOLOGOUS PHASE}

PHN was induced in two groups of rats immunosuppressed to prevent a host antibody response. This was done to eliminate any role for an autologous phase reaction involving glomerular deposition of rat IgG in mediating the proteinuria which occurs at 4-5 d in PHN. $1 \mathrm{~d}$ before administration of a proteinuric dose of $30 \mathrm{mg}$ of anti-Fx1A IgG i.v.: one group of nine rats received 860 rad of total body irradiation administered from a dual ${ }^{137} \mathrm{Cs}$ source small animal irradiator (Gammocell 40, Atomic Energy of Canada Ltd., Toronto, Canada) at a dose rate of $140 \mathrm{rad} / \mathrm{min}$. A second group of seven rats was given a single dose of cyclophosphamide (Cytoxan, Mead Johnson \& Co., Evansville, Ind.), $150 \mathrm{mg} / \mathrm{kg}$ i.p. A control group of six rats received $1 \mathrm{ml}$ of saline i.p. Urine protein excretion of all rats in the three groups was measured on days 4-5 after antibody administration, and renal biopsies were obtained and studied for deposition of sheep IgG, rat C3, and rat IgG by direct immunofluorescence (IF).

\section{IN VIVO DEPOSITION OF RAT C3}

In vivo deposition of the third component of rat complement (C3) in PHN was assessed by direct IF of renal biopsies from four rats obtained $20 \mathrm{~min}, 4 \mathrm{~h}$, and daily for $5 \mathrm{~d}$ after anti-Fx1A injection using the fluorescein-conjugated IgG fraction of an anti serum to rat $\mathrm{C} 3$.

\section{IN VITRO COMPLEMENT FIXATION}

The ability of glomerular immune deposits to bind human C3 was assessed in vitro by incubating sections of kidney from PHN rats with fresh or heat-inactivated human serum and staining for human $\mathrm{C} 3$ by direct IF as described below. In addition, the various anti-FxlA reagents used in the study were tested for in vitro complement fixing ability before injection by layering them on sections of normal rat kidney to produce proximal tubular brush border staining followed by exposure to fresh human serum and staining for human C3.

\section{SERUM COMPLEMENT LEVELS}

Serum C3 levels were measured during the development of $\mathrm{PHN}$ in six rats on serum samples obtained from the tail vein $30 \mathrm{~min}, 3 \mathrm{~h}$, and $24 \mathrm{~h}$ after antibody injection and then daily for $5 \mathrm{~d}$. C3 levels were determined by Mancini single radial immunodiffusion (23) and expressed as a percentage of the base-line $\mathrm{C} 3$ level in each animal measured before antibody injection. Control rats received injections of normal sheep IgG.

\section{COMPLEMENT DEPLETION STUDIES}

The role of complement in the development of proteinuria in PHN was assessed by depleting rats of $\mathrm{C} 3$ for $5 \mathrm{~d}$ by repeated injections of purified cobra venom factor (CVF) prepared as described below. After obtaining a base-line serum sample for C3 level, 11 rats were complement depleted by an initial injection of $300 \mathrm{U} / \mathrm{kg}$ of CVF i.p. in four divided doses starting $24 \mathrm{~h}$ before injection of $25 \mathrm{mg}$ of anti-FxlA antibody i.v. followed by daily injections of CVF, $100 \mathrm{U} / \mathrm{kg}$ i.p., for $5 \mathrm{~d}$ as described by Cochrane et al. (14). Daily serum C3 levels were measured as described above. A control group of 11 age-matched rats were injected in parallel with the same dose of anti-Fx1A but were not complement depleted. Urine protein excretion was measured in both groups on days 4-5. This study was repeated using five rats, complement depleted with CVF that had been treated as described below to inactivate phospholipase $A_{2}$ and five control rats injected with saline. 


\section{EFFECT OF COMPLEMENT DEPLETION ON ANTIBODY DEPOSITION}

To ensure that the effect of complement depletion on the development of proteinuria in PHN was not due to altered glomerular antibody deposition, in vivo glomerular antibody binding was evaluated by IF and electron microscopy of renal biopsies and by quantitative techniques using ${ }^{125}$ I-labeled antibody as described below. 18 rats, 9 of which were treated with CVF as described above and 9 of which received daily injections of saline, were given $24 \mathrm{mg}$ anti-Fx $1 \mathrm{~A}$ IgG- ${ }^{125} \mathrm{I}$ i.v. At killing on day 5 the kidneys were perfused in situ, tissue was obtained for IF and electron microscopy, and antibody deposition was measured from the kidney radioactivity.

\section{EFFECT OF CVF ON PROTEINURIA IN OTHER MODELS}

To determine whether the inhibition of proteinuria by $\mathrm{CVF}$ in PHN was indeed due to C3 depletion and absence of C3 from glomerular immune deposits, or to some other unidentified effect of CVF on glomerular permeability, CVF was administered to $\mathrm{PHN}$ rats with established proteinuria and to rats during the development of nonimmunologic glomerular injury.

Of 11 rats with fully developed $\mathrm{PHN}$ and proteinuria $11 \mathrm{~d}$ after anti-FxlA administration, 5 were complement-depleted for $3 \mathrm{~d}$ with CVF as described above and the other 6 received no treatment. Urine protein excretion was measured in both groups before and after CVF. In a second study eight rats were given aminonucleoside of puromycin (ICN Pharmaceuticals, Inc., Covina, Calif.) $100 \mathrm{mg} / \mathrm{kg}$ i.v. Four were treated as above with CVF from the day before administration of aminonucleoside and for $6 \mathrm{~d}$ thereafter and the remaining four were given daily injections of normal saline on the same schedule. Urine protein excretion was measured in both groups on days $6-7$.

\section{STUDIES WITH NONCOMPLEMENT-FIXING ANTIBODIES}

To further establish the dependency of proteinuria upon in vivo fixation of complement, PHN was induced by two types of noncomplement-fixing anti-FxlA antibodies. Gamma 1 (complement-fixing) and gamma 2 (noncomplement-fixing) subclasses of sheep anti-FxlA IgG prepared, trace labeled with ${ }^{125} \mathrm{I}$, and characterized as described below, were injected into two separate groups of six rats per group. Urine protein excretion was measured in both groups on days 4-5. At killing on day 5 , renal tissue was obtained for IF and electron microscopy, and glomerular antibody deposits were quantified as described below. The dose of $\gamma 1$ anti-Fx $1 \mathrm{~A}$ IgG $(15 \mathrm{mg})$ was shown in a pilot experiment to produce proteinuria on days $4-5$. The doses of $\gamma 2$ anti-FxlA IgG, $18 \mathrm{mg}$ (three rats) and 22 mg (three rats), were chosen to ensure that the amount of glomerular binding of $\gamma 2$ antibody was at least equivalent to that of $\gamma 1$ antibody. $F\left(a^{\prime}\right)_{2}$ fragments of anti-FxlA prepared, trace labeled with ${ }^{125} \mathrm{I}$ and characterized as described below, were given intravenously to nine rats. Urine protein excretion was measured on days 4-5 before killing on day 5 when renal tissue was obtained for IF and electron microscopy, and glomerular antibody deposits were quantified as described below. The doses of anti-FxlA F $\left(\mathrm{ab}^{\prime}\right)_{2}, 20-40 \mathrm{mg}$ (the molar equivalents of 35-70 $\mathrm{mg}$ of $\mathrm{IgG}$ ), were purposely chosen to be greater than the dose of anti-FxlA IgG $(20 \mathrm{mg})$ that regularly produces proteinuria on days $4-5$ in an attempt to ensure that the amount of glomerular bound $F\left(a^{\prime}\right)_{2}$ exceeded the proteinuric threshold previously defined in this model (18).

\section{ROLE OF NEUTROPHILS}

The role of neutrophils in the pathogenesis of proteinuria in PHN was evaluated in two experiments. Histologic evidence for participation of neutrophils in the glomerular lesion of PHN was sought in biopsies obtained from at least five rats 10 $\min , 1,4,12$, and $24 \mathrm{~h}$, and $2,3,4$, and $5 \mathrm{~d}$ after injection of 25 $\mathrm{mg}$ of anti-FxlA. Five control rats were injected with $25 \mathrm{mg}$ of normal sheep IgG. Tissue for light microscopy was processed as described below. Neutrophils were counted in at least 10 glomeruli in two micron-coded sections from each biopsy stained with periodic acid-Schiff and expressed as neutrophils/ 10 glomeruli. (Neutrophil counts were generously provided by Dr. Magda Stilmant of the Mallory Institute of Pathology, Boston City Hospital.)

A group of five rats was depleted of neutrophils by injection of a specific rabbit anti-rat neutrophil globulin, $0.8 \mathrm{ml}$ i.v., which was prepared as described below and given every $12 \mathrm{~h}$ from the morning before $\mathrm{PHN}$ induction and for $5 \mathrm{~d}$ thereafter. A group of six littermates with PHN were given normal rabbit globulin on the same schedule. Urine protein excretion was measured in both groups on days $3-4$ and on days 4-5. Circulating neutrophils were measured on blood obtained from the tail vein before each morning dose of antiserum. Total peripheral leukocyte counts were measured on a Coulter counter model ZB1 (Coulter Electronics, Inc., Hialeah, Fla.), and the percentage of neutrophils obtained by counting 200 cells on a smear of peripheral blood stained with Wright's stain. Only rats with less than 200 neutrophils $/ \mathrm{mm}^{3}$ throughout the 5-d period of the study were considered to be neutrophil depleted.

\section{Technical details}

\section{Production AND CHARACTERIZATION OF ANTI-RAT FxlA IgG, $\gamma 1$ AND $\gamma 2$ SUBCLASSES, AND \\ $\mathrm{F}\left(\mathrm{ab}^{\prime}\right)_{2}$ FRAGMENTS}

Sheep were hyperimmunized with rat FxlA prepared as described by Edgington et al. (24) and emulsified in complete Freund's adjuvant (Difco Laboratories, Detroit, Mich.). After three to four monthly injections of 75-100 mg of FxlA, IgG antibody was isolated from a $50 \%$ ammonium sulfate precipitate of heat-inactivated $\left(56^{\circ} \mathrm{C}, 30 \mathrm{~min}\right)$ whole serum by ionexchange chromatography on DEAE-Sephadex (Pharmacia Fine Chemicals, Inc., Piscataway, N. J.) and absorbed with rat serum, erythrocytes, leukocytes, and platelets.

The $\gamma 1$ and $\gamma 2$ subclasses of sheep IgG were separated from a $50 \%$ ammonium sulfate precipitate of whole antiserum by ion-exchange chromatography on DEAE-Sephacel (Pharmacia Fine Chemicals, Inc.) using $0.0175 \mathrm{M}$ sodium phosphate buffer, $\mathrm{pH} 7.4$, to elute the more cationic fraction $(\gamma 2)$ followed by application of a linear $\mathrm{NaCl}$ gradient to $0.3 \mathrm{M}$ to obtain the more anionic $(\gamma \mathrm{l})$ fraction. The two major IgG peaks were pooled separately, concentrated in an Amicon PM 30 ultrafilter (Amicon Corp. Scientific Sys. Div., Lexington, Mass.) to $\sim 10$ $\mathrm{mg} / \mathrm{ml}$ and stored at $-70^{\circ} \mathrm{C}$ until used.

$\left.\mathrm{F}(\mathrm{ab})_{2}\right)_{2}$ fragments were prepared from IgG isolated from antiFxlA antiserum as described above by digestion with pepsin according to the method of Nisonoff et al. (25). Approximately $100 \mathrm{mg}$ of $\mathrm{IgG}$, at a concentration of $10-20 \mathrm{mg} / \mathrm{ml}$, was incubated with pepsin (crystallized twice, Worthington 
Biochemical Corp., Freehold, N. J.) at a protein:enzyme ratio of $100: 1$ in $0.2 \mathrm{M}$ acetate buffer, $\mathrm{pH} 4.5$, at $37^{\circ} \mathrm{C}$ for $18 \mathrm{~h}$. Digestion was terminated by raising the $\mathrm{pH}$ to 8.0 with $1.0 \mathrm{~N}$ sodium hydroxide. $\mathrm{F}\left(\mathrm{ab} \mathrm{b}^{\prime}\right)_{2}$ fragments were separated from undigested IgG ( $<10 \%$ of total protein) and smaller fragments by gel filtration chromatography on Sephadex G-150 (Pharmacia Fine Chemicals, Inc.). Samples of $50 \mathrm{mg}$ in $1.5 \mathrm{ml}$ were applied to a $1.5 \times 90-\mathrm{cm}$ column and eluted with $0.01 \mathrm{M}$ sodium phosphate- $0.2 \mathrm{M}$ sodium chloride buffer, $\mathrm{pH} 8.2$, at room temperature. The $\mathrm{F}\left(\mathrm{ab}^{\prime}\right)_{2}$ peak was concentrated to 8.5 $\mathrm{mg} / \mathrm{ml}$, dialyzed against $0.02 \mathrm{M}$ phosphate-buffered saline, $\mathrm{pH}$ 7.2 , and stored at $-70^{\circ} \mathrm{C}$ until used. The molecular size of $\mathrm{F}\left(\mathrm{ab}^{\prime}\right)_{2}$ fragments of sheep IgG $(96,000$ daltons $)$ was calculated from the elution volume from the Sephadex G-150 column precalibrated with blue dextran, aldolase, ovalbumin, chymotrypsinogen, and ribonuclease $A$.

In addition to the chromatographic elution profiles obtained in preparing $\operatorname{IgG}, \gamma 1$ and $\gamma 2$ subclasses and $F\left(\mathrm{ab}^{\prime}\right)_{2}$ fragments, the following procedures were performed to further characterize each reagent. To assess purity and specificity, immunoelectrophoresis and micro-Ouchterlony reactivity in $1 \%$ agarose was determined against whole rat serum and to sheep IgG (N. L. Cappel Laboratories Inc., Cochranville, Pa.) $(26,27)$. The isoelectric points of each reagent were determined by gel isoelectric focusing (generously performed by Dr. Helmut Rennke of the Peter Bent Brigham Hospital) using a model M-150 slab electrofocusing apparatus (MRA Corp., Clearwater, Fla.) and techniques described in detail elsewhere $(28,29)$. Antibody reactivity in vitro with glomeruli and proximal tubular brush borders was determined by indirect IF on cryostat sections of normal kidney stained with fluorescein-conjugated antiserum to sheep IgG (N. L. Cappel Laboratories Inc.) $(17,18)$. In vitro complement-fixing ability was assessed by injecting rats with $\operatorname{IgG}$ or $F\left(a b^{\prime}\right)_{2}$ antibodies and studying kidneys $5 \mathrm{~d}$ later by IF and electron microscopy as described below. In addition, the in vivo glomerular binding activity of each preparation was quantitated as outlined below using reagents labeled with ${ }^{125} \mathrm{I}$. The protein concentrations of purified preparations of sheep antibody were measured by the Biuret method.

\section{INDUCTION OF PHN AND QUANTITATION OF ANTIBODY DEPOSITS}

PHN was induced in male Sprague-Dawley rats weighing 140-200 g (CD, Charles River Breeding Laboratories, Wilmington, Mass.) by intravenous injection of various doses of sheep anti-FxlA IgG, $\gamma 1, \gamma 2$ or $\mathrm{F}\left(\mathrm{ab}^{\prime}\right)_{2}$. All studies of proteinuria and glomerular antibody deposition were performed $5 \mathrm{~d}$ later. This time was selected on the basis of previous studies in this model demonstrating that proteinuria occurs 4-5 d after injection of a nephritogenic quantity of antibody, and that autologous phase deposition of rat IgG in glomeruli is minimal or absent at $5 \mathrm{~d}(18,22)$. Urine protein excretion was measured on 24-h urine specimens collected from animals in individual metabolic cages with free access to water. Protein content was measured by a sulfosalicylic acid method (30) using a commercial whole serum standard (LabTrol, Dade Div. American Hospital Supply Corp., Miami, Fla.). The urine protein composition was determined by agarose gel electrophoresis and densitometry of urine samples concentrated 20-fold (11).

The amount of antibody deposited in kidneys and glomeruli of individual rats injected with various ${ }^{125}$ I-labeled preparations was measured by methods described in detail elsewhere (18). For the purposes of this study, total kidney bound antibody of each rat was determined $5 \mathrm{~d}$ after radiolabeled antibody injection by counting perfused whole kidneys and correcting for background, decay, and nonspecific binding as described (18). Antibody specifically bound in glomeruli was measured from the radioactivity of glomeruli isolated from kidneys of individual rats using differential sieving techniques (18).

\section{COMPLEMENT AND NEUTROPHIL STUDIES}

Preparation of anti-rat C3. Anti-rat C3 was prepared by immunizing rabbits three times with a repeatedly washed precipitate of boiled zymosan (Sigma Chemical Co., St. Louis, Mo.) and fresh rat serum as described by Mardiney and MüllerEberhard (31). After absorption with lyophilized plasma from rats decomplemented with $\mathrm{CVF}$ as described above, anti-C3 made a characteristic bimodal arc in the $\beta 1$ globulin region on immunoelectrophoretic analysis reacting primarily with the faster moving arc in fresh serum and with the slower moving arc in aged or heat-inactivated $\left(56^{\circ} \mathrm{C}, 30 \mathrm{~min}\right)$ rat serum $(31,32)$. Anti-C3 stained deposits of human antinuclear antibody on cryostat sections of normal rat kidney after exposure to fresh rat serum, as described below in the in vitro complement fixation test, but failed to stain antibody-treated sections exposed to heat-inactivated rat serum. Fluorescein conjugation of antibody and subsequent characterization was carried out as described in detail elsewhere $(20,22)$.

In vitro C3 fixation. Washed, unfixed cryostat sections of PHN kidneys and normal rat kidney that had been previously incubated with the various anti-FxlA reagents were tested for in vitro complement-fixing ability by incubating them with the appropriate dilutions of fresh or heat-inactivated human serum in veronal buffer at $20^{\circ} \mathrm{C}$ for 45 min followed by washing and staining for human C3 by direct IF $(11,33)$. Human antinuclear antibody-containing serum was used as a positive control for the in vitro complement-fixation procedures (33).

CVF. CVF obtained from Naja naja (Cordis Laboratories Inc., Miami, Fla.) was isolated by ion-exchange chromatography on DEAE-cellulose (Whatman, Inc., Clifton, N. J.) or DEAE-Sephadex followed by gel filtration chromatography on Sephadex G-200. The final product was free of contamination with lecithinase (phospholipase $A_{2}$ ) as judged by failure to lyse guinea pig erythrocytes incubated with CVF and egg yolk (34). To further ensure that phospholipase $A_{2}$ contamination was not responsible for the results observed, complementdepletion studies were also carried out using CVF that had been incubated with $0.1 \mathrm{mM}$ para-bromophenacyl bromide (Aldrich Chemical Co., Inc., Milwaukee, Wis.) at $37^{\circ} \mathrm{C}$ and $\mathrm{pH}$ 8.0 for $30 \mathrm{~min}$ as described by Shaw et al. (34), to inactivate any remaining phospholipase $A_{2}$.

Preparation of anti-rat neutrophil serum. Rat neutrophils were isolated by administering $10 \mathrm{ml}$ of $0.1 \%$ oyster glycogen (Sigma Chemical Co.) in saline or Hanks' balanced salt solution containing $1 \mathrm{U} / \mathrm{ml}$ of heparin i.p. on two successive days to $12300-400 \mathrm{~g}$ Sprague-Dawley rats as described by Cochrane et al. (9). Peritoneal exudates were collected $3 \mathrm{~h}$ after the second injection. The washed cell pellet, which contained $>90 \%$ neutrophils, was emulsified in incomplete Freund's adjuvant (Difco Laboratories) and used to immunize three rabbits. Antiserum, collected 3 wk later, was absorbed with lyophilized whole rat serum and neutrophil-free rat erythrocytes obtained from 18 rats $24 \mathrm{~h}$ after administration of nitrogen mustard (Mustargen hydrochloride, Merck, Sharp \& Dohme Canada Ltd., Quebec, Canada), $2 \mathrm{mg} / \mathrm{kg}$ i.p. Additional absorptions were carried out with rat lymphocytes and thymocytes obtained from mesenteric lymph nodes and thymuses of 10 rats. The globulin fraction of the absorbed antiserum was isolated by a single $50 \%$ ammonium sulfate 
precipitation. It was reconstituted to half the original volume and dialyzed extensively against phosphate-buffered saline, $\mathrm{pH} 7.2$, and stored at $-70^{\circ} \mathrm{C}$ until used.

\section{TISSUE PROCESSING AND IF PROCEDURES}

Renal tissue obtained by wedge biopsy of kidneys under ether anesthesia was processed for light microscopy, IF, and electron microscopy as described in detail elsewhere (20). Tissue fixed in $10 \%$ neutral formalin, sectioned at $2 \mu \mathrm{m}$ and stained with periodic acid-Schiff reagent was examined for glomerular neutrophil counts as described above as well as other histological changes.

Direct and indirect IF procedures were performed on tissue snap-frozen in dry ice-isopentane, and cryostat sections fixed in ether-alcohol were studied using techniques and controls described previously $(17,20)$. All biopsies were stained with the IgG fraction of monospecific antisera to sheep IgG and rat IgG, C3 and albumin (N. L. Cappel Laboratories) conjugated with fluorescein isothiocyanate (Bio-Quest, BBL Falcon Products, Div. of Becton, Dickinson and Co., Cockeysville, Md.) by a dialysis method (35). Antibody to rat IgG was not cross-reactive with sheep IgG by immunoprecipitin or IF analysis.

Antisera to human C3 (N. L. Cappel Laboratories) and human $\mathrm{Cl}_{q}$ (Calbiochem-Behring Corp., American Hoechst Corp., San Diego, Calif.) were used in the in vitro complementfixation studies. IF was evaluated and photographed on a Leitz Ortholux II microscope equipped with a Ploempak 2.2 vertical fluorescence illuminator (E. Leitz Inc., Rockleigh, N. J.). Tissue for electron microscopy was immersion-fixed in glutaraldehyde and postfixed in osmium followed by en bloc staining in uranyl acetate for $30 \mathrm{~min}$ before embedding in Epon 812 (Shell Chemical Co., Houston, Tex.).

\section{Statistical anALYSIS}

Student's $t$ test for unpaired data was used to analyze the results of renal binding of labeled antibody and urine protein excretion (36). Analysis of variance was used to evaluate the changes in daily serum C3 levels (36). Differences were regarded as significant when $P<0.05$. All values are expressed as mean \pm 1 SD unless otherwise stated.

\section{RESULTS}

Characteristics of the heterologous phase of PHN. The glomerular lesion induced by anti-FxlA was identical to that described in detail $(17,18,22)$. Granular deposits of sheep IgG were seen within minutes by IF and increased in amount until day 5 . Trace deposits of rat IgG were detectable in some glomeruli of proteinuric rats on days 4 and 5. Proteinuria was first apparent on days 3-4 in some rats, but on days 4-5 virtually all rats were proteinuric. The urine protein excretion on day 5 was nonselective with only $75 \%$ representing albumin.

Suppression of the host response to heterologous IgG. The results of immunosuppression studies demonstrated that the development of proteinuria in PHN is not dependent on an autologous phase reaction since all rats given total body irradiation or cyclophosphamide became proteinuric in the absence of rat IgG deposits in glomeruli. Lethally irradiated rats $(n=9)$ excreted $47 \pm 37.1$ (range: $10-117$ ) $\mathrm{mg} / 24 \mathrm{~h}$, which was not significantly different from control rats $(n=6)$, which excreted $83 \pm 44.9$ (range: $25-123) \mathrm{mg} / 24 \mathrm{~h}(P$ $<0.2)$. Rats given cyclophosphamide $(n=7)$ excreted $42 \pm 13.5$ (range: 24-61) $\mathrm{mg} / 24 \mathrm{~h}$ which was significantly less than controls $(P<0.05)$ but still clearly abnormal. The upper $99 \%$ confidence limit of protein excretion in 20 normal age-matched rats was $3.5 \mathrm{mg} /$ $24 \mathrm{~h}$. There were no glomerular deposits of rat IgG in the renal biopsies on day 5 in any of the rats in the two immunosuppressed groups. In contrast, all rats in the control group had trace-1+ granular capillary wall deposits of rat IgG by IF on day 5 .

In vivo deposition of rat C.3. Sequential biopsies of four rats injected with unfractionated anti-FxlA IgG showed that $\mathrm{C} 3$ was first detectale by IF in glomerular deposits at about $24 \mathrm{~h}$. By day 5, C3 deposits were identical in pattern and distribution to the deposits of sheep IgG, though of slightly less intensity.

In vitro C.3 binding. When sections of kidney obtained on day 5 from four rats with PHN were incubated with fresh or heat-inactivated human serum and stained for human C3, glomerular deposits bound C3 in fresh, but not in heat-inactivated, serum. Similarly, when stained for human Clq, finely granular deposits were also detected. When normal rat kidney sections were first incubated with anti-FxlA to produce proximal tubular epithelial brush border deposits, followed by incubation with fresh or inactivated human serum and then stained for C3, positive brush border staining was seen with fresh, but not with inactivated serum. Proximal tubules and glomeruli of normal rat kidney incubated with normal human serum without prior incubation with anti-Fx1A did not fix $\mathrm{C} 3$ or Clq.

Serum C.3 in PHN. Fig. 1 shows the changes in serum C3 in six rats injected with a proteinuric dose of anti-FxlA. Each rat served as its own control. The serum C3 level at each time interval is expressed as a percentage of the level obtained before antibody injection. The initial rise in serum $\mathrm{C} 3$ at $30 \mathrm{~min}$ and $3 \mathrm{~h}$ (Fig. 1) coincided with a transient rise in hematocrit to $57 \pm 1.9 \%$ at $30 \mathrm{~min}$ and $46 \pm 3.3 \%$ at $3 \mathrm{~h}$ from a normal level of $42 \pm 1.4 \%$. The hematocrit returned to the preinjection level by $24 \mathrm{~h}$. When corrected for this change in hematocrit, a slight but insignificant fall in C3 levels was found at $30 \mathrm{~min}$ and $3 \mathrm{~h}$ (Fig. 1). Serum C3 levels then rose significantly above base line at $2 \mathrm{~d}$ $(P<0.02)$ and remained elevated for the remainder of the study (Fig. 1).

Effect of complement depletion on proteinuria. Serum C3 measured daily in 13 rats treated with CVF from the day before anti-FxlA antibody injection until day 5 was reduced to $<10 \%$ of the pretreatment level throughout the study period in all but one rat. Serum C3 


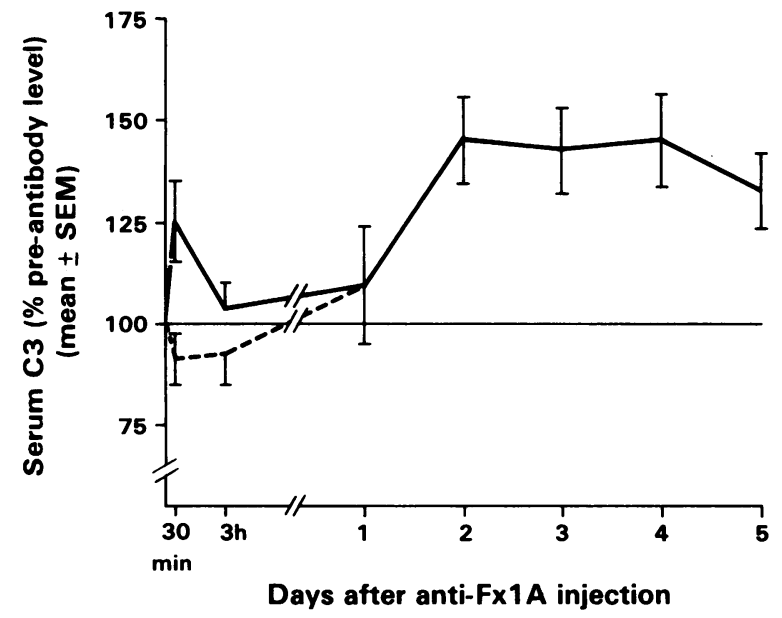

FIGURE 1 Serum C3 levels measured for 5 days after injection of a proteinuric dose of anti-FxlA antibody. The dashed line represents values corrected for a transient decrease in plasma volume $30 \mathrm{~min}$ and $1 \mathrm{~h}$ after antibody injection.

values, measured just before induction of PHN and 1 and $5 \mathrm{~d}$ thereafter in CVF and saline-treated rats are shown in Table I. A marked inhibition of proteinuria on days 4-5 was found in CVF-treated rats as compared to saline-treated controls (Table I) $(P<0.001)$. CVF, treated to inactive phospholipase $A_{2}$, was as equally effective as untreated CVF in depleting five PHN rats of C3 $(6 \pm 2.1 \%$ of base line on day 5$)$ and in preventing the development of proteinuria $(7 \pm 5.5 \mathrm{mg} / 24 \mathrm{~h})$. These results are included in those shown in Table $\mathrm{I}$.

Glomerular IgG and C3 deposition in complementdepleted PHN rats. Renal biopsies on day 5 in six CVF treated rats with PHN showed diffuse, granular deposition of sheep IgG identical to that of salinetreated controls but deposition of C3 in vivo on glomerular capillary walls was absent. When sections of these biopsies were incubated with fresh, normal, human serum followed by staining for human C3, in vitro fixation of human C3 was found that was identical to that found in kidneys from noncomplement-depleted rats. By electron microscopy CVF-treated PHN rats had discrete, subepithelial electron dense deposits identical to those previously demonstrated in noncomplementdepleted PHN rats $(17,18,22)$.

When the amount of ${ }^{125}$ I-labeled anti-FxlA deposition was measured in kidneys from nine rats treated with CVF to deplete complement and compared to the amount deposited in kidneys of nine saline-treated controls, the amount of specific antibody deposition was not significantly different in the two groups (Table I) $(P>0.5)$.

Effect of CVF on established proteinuria in PHN. 11 rats with fully developed PHN on day 11 and established proteinuria $(196 \pm 35.1 \mathrm{mg} / 24 \mathrm{~h})$ were randomly divided into two groups. Five rats injected daily with $\mathrm{CVF}$ excreted $217 \pm 86.6 \mathrm{mg}$ protein $/ 24 \mathrm{~h}$ after treatment for $3 \mathrm{~d}$, whereas six untreated controls excreted $242 \pm 32.5 \mathrm{mg}$ protein $/ 24 \mathrm{~h}(P>0.5)$.

Effect of CVF on the development of proteinuria in nonimmunologic glomerular injury. Eight rats given aminonucleoside of puromycin to induce nonimmunologic glomerular injury were randomly divided into two groups of four rats each. One group was treated with CVF from the day before aminonucleoside administration and for $6 \mathrm{~d}$ thereafter. The other group was treated with saline according to the same schedule. Proteinuria was present in all animals on days $6-7$, and there was no significant difference between the groups (CVF: $205 \pm 61.2 \mathrm{mg} / 24 \mathrm{~h}$; saline: $249 \pm 46.4 \mathrm{mg} / 24 \mathrm{~h}, P>0.25)$.

Noncomplement-fixing antibodies in the induction of PHN. By immunoelectrophoresis, the subclasses of sheep IgG each made a single arc in the gamma region with antiserum to whole sheep serum and sheep IgG, but the $\gamma 1$ subclass migrated more rapidly than the $\gamma 2$ subclass. This finding was confirmed by isoelectric focusing that showed no overlap in isoelectric point (pI) $(\gamma 1: 5.3-7.8 ; \gamma 2: 8.1-9.6)$. The presence of antibody activity against FxlA in both subclasses was confirmed by micro-Ouchterlony, and reactivity with proximal tubular brush border was demonstrated by indirect IF

TABLE I

Serum C.3, Urine Protein Excretion, and Renal Binding of ${ }^{125}$ I-labeled Anti-FxlA in PHN Rats Treated with CVF or Saline

\begin{tabular}{|c|c|c|c|c|c|}
\hline \multirow[b]{2}{*}{ Group } & \multicolumn{3}{|c|}{ Serum C3 } & \multirow{2}{*}{$\frac{\text { Urine Protein }}{\text { Days 4-5 }}$} & \multirow{2}{*}{$\begin{array}{l}\text { Kidney-bound } \\
\text { antibody* }\end{array}$} \\
\hline & Day 0 & Day 1 & Day 5 & & \\
\hline & \multicolumn{3}{|c|}{ \% base line } & $m g / d$ & $\mu g / 2$ kidneys \\
\hline Saline & $100(6)$ & $109 \pm 35.4(6)$ & $133 \pm 21.0(6)$ & $70 \pm 15.0(16)$ & $188 \pm 35(9)$ \\
\hline CVF & $5 \pm 0.8(6)$ & $7 \pm 1.5$ & $6 \pm 4.2$ & $4 \pm 1.0 \quad(16)$ & $191 \pm 22(9)$ \\
\hline
\end{tabular}

All values are mean $\pm S E M$, number studied is in parentheses.

* ${ }^{125}$ I-labeled anti-Fx1A IgG measured in kidneys on day 5 . 
on normal rat kidney. When injected to produce glomerular deposits, the $\gamma 1$ subclass fixed heterologous C3 in vitro (Fig. 2c) but the $\gamma 2$ subclass did not (Fig. 2f).

The results of urine protein excretion on days 4-5 and glomerular antibody binding on day 5 in two groups of rats given either $\gamma 1$ or $\gamma 2$ anti-Fx $1 \mathrm{~A}$ that had been trace-labeled with ${ }^{125} \mathrm{I}$ are shown in Fig. 3. All six rats given $\gamma 1$ anti-FxlA were proteinuric on days 4-5 $(41 \pm 22 \mathrm{mg} / 24 \mathrm{~h}$ ) (Fig. 3). Urine protein excretion in the six rats injected with $\gamma 2$ anti-FxlA did not exceed 7.4 $\mathrm{mg} / 24 \mathrm{~h}$ (mean: $5 \pm 1.6 \mathrm{mg} / 24 \mathrm{~h}$ ) despite the fact that in four rats the amount of glomerular-bound antibody was greater than that in three rats given $\gamma 1$ anti-FxlA, which were proteinuric (Fig. 3). Glomerular antibody binding ( $\gamma 1: 91 \pm 32.1 \mu \mathrm{g} / 2$ kidneys; $\gamma 2: 66 \pm 12.8 \mu \mathrm{g} / 2$ kidneys $)$ was not significantly different in the two groups $(P<0.2)$, whereas the difference in urine protein excretion on days $4-5$ was highly significant $(P<0.005)$ (Fig. 3). IF of renal tissue obtained at sacrifice on day 5 showed diffuse, granular, glomerular capillary wall staining for sheep IgG in rats injected with either $\gamma 1$ or $\gamma 2$ anti-Fx1A (Fig. 2a and 2d). Tubular brush border staining was found only in proteinuric rats given $\gamma 1$ antiFxlA. Rat IgG was found in trace amounts in both groups. Glomeruli of rats given $\gamma 2$ anti-Fx1A had minimal or no deposits of rat C3 (Fig. 2e), whereas those of rats given $\gamma 1$ anti-FxlA had diffuse, granular capillary wall staining for rat $\mathrm{C} 3$ (Fig. 2b). Glomerular deposits of $\gamma 1$ anti-FxlA fixed human C3 in vitro (Fig. 2c), whereas those of $\gamma 2$ anti-FxlA did not (Fig. 2f).

By immunoelectrophoresis against antiserum to whole sheep serum and to sheep IgG, anti-Fx $1 \mathrm{~A} \mathrm{~F}\left(\mathrm{ab}^{\prime}\right)_{2}$ fragments made a single arc of precipitation in the same region as native sheep IgG and the pI range was 6.1-9.6 as compared to 4.8-9.6 for native sheep IgG anti-Fx1A. Micro-Ouchterlony revealed the same three lines of reactivity against $F_{x} 1 \mathrm{~A}$ as previously shown with native IgG anti-FxlA (17, 24). By indirect IF, F(ab') fragments of anti-FxlA produced intense proximal tubular epithelial cell brush border staining and faint, diffuse glomerular staining for sheep IgG on sections of normal rat kidney but failed to fix $\mathrm{C} 3$ in vitro. The results of urine protein excretion on days $4-5$ of seven rats given 20-40 mg of radiolabeled anti-FxlA F $\left(\mathrm{ab}^{\prime}\right)_{2}$ antibodies was not significantly different from that of normal, age-matched rats (Fig. 3). The maximum glomerular antibody binding achieved on day 5 was, however, less than the minimum amount of $\gamma 1 \mathrm{IgG}$ that caused proteinuria (Fig. 3). IF of the kidneys obtained at sacrifice on day 5 showed diffuse, discrete, very fine, granular staining of sheep IgG on the glomerular capillary wall, and intense brush border staining. Staining for rat C3 was negative. Electron microscopy showed numerous, small subepithelial electron-dense deposits located mainly in the region of filtration slit pores.
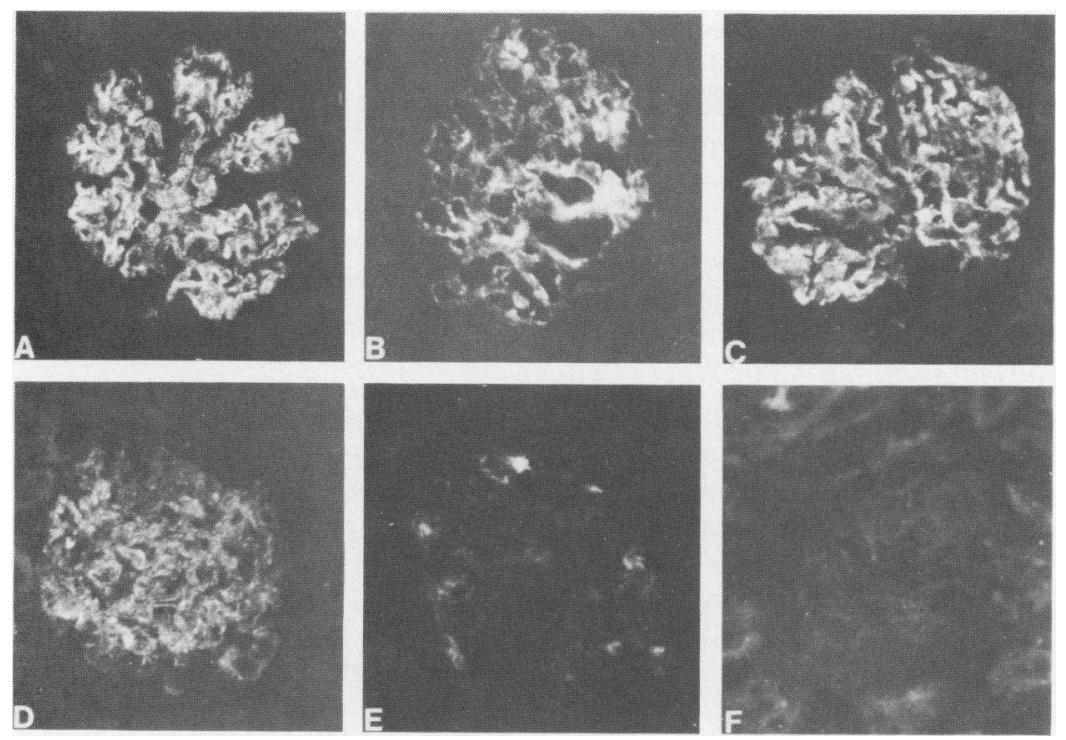

FIGURE 2 Immunofluorescent photomicrographs $5 \mathrm{~d}$ after injection of $\gamma_{1}(\mathrm{a}-\mathrm{c})$ or $\gamma_{2}$ (d-f) anti-FxlA IgG. Both subclasses of antibody form typical finely granular subepithelial deposits on glomerular capillary walls (a and d). Rat C3 is deposited in vivo in a pattern similar to that of IgG in rats with $\gamma_{1}$ deposits (b) but is absent in rats with $\gamma_{2}$ deposits (e). Exposure to fresh human serum in vitro results in C3 fixation by $\gamma_{1}$ deposits (c), but $\gamma_{2}$ deposits do not fix heterologous C3 in vitro (f). (Original magnifications $450 \times$ ). 


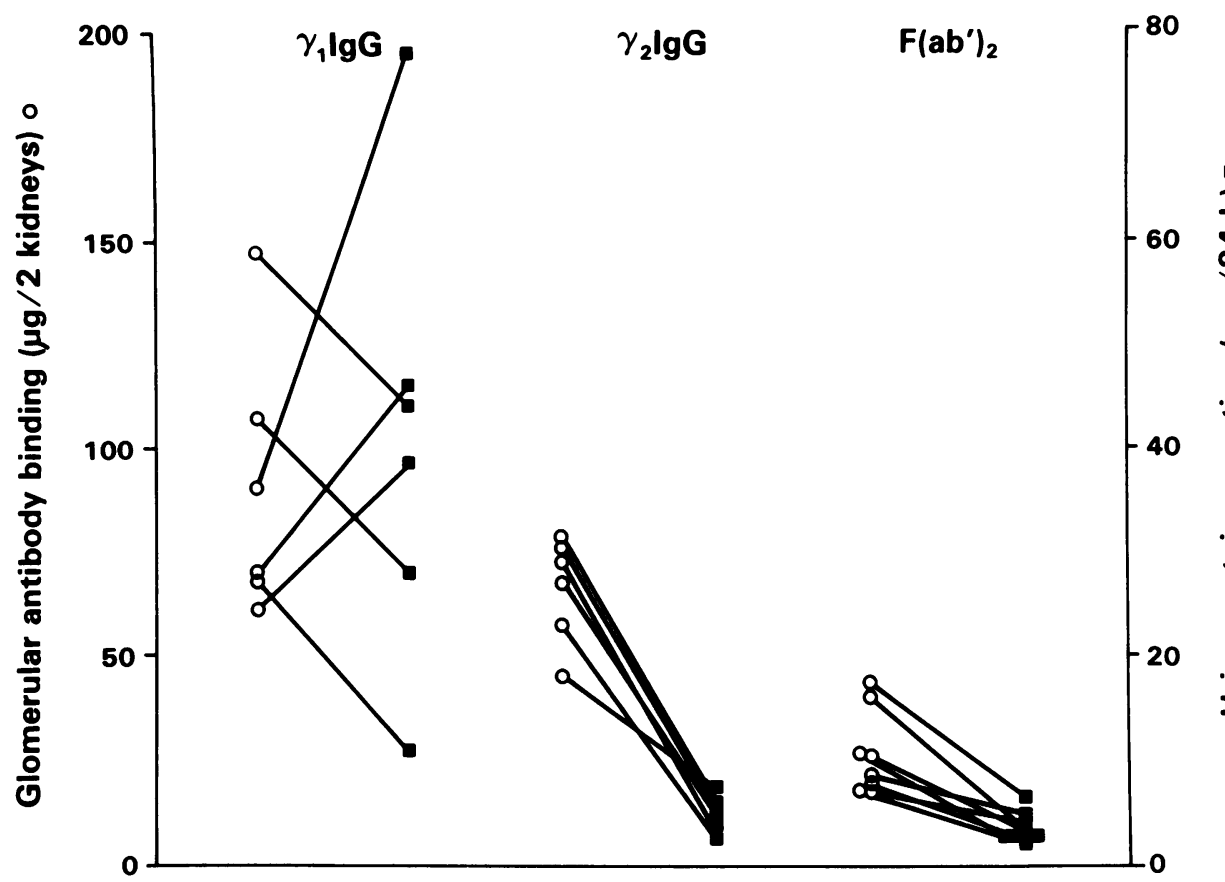

FIGURE 3 Glomerular antibody binding (open circles) and urine protein excretion (closed squares) 5 days after injection of rats with various doses of the $\gamma_{1}$ and $\gamma_{2}$ subclasses and the $F\left(a^{\prime}\right)_{2}$ fragment of anti-FxlA IgG. All rats injected with complement-fixing $\gamma_{1}$ were proteinuric. Rats injected with noncomplement-fixing $\gamma_{2}$ did not become proteinuric, although glomerular binding of $\gamma_{2}$ antibody in several animals exceeded the amount of antibody deposition in several proteinuric rats in the $\gamma 1$ group.

Neutrophils in the pathogenesis of proteinuria in $P H N$. Sequential renal biopsies obtained from rats injected with a proteinuric dose of anti-FxlA were examined by light microscopy for the presence of neutrophils within the glomeruli. Biopsies from four rats at each of nine time intervals from 10 min to $5 \mathrm{~d}$ revealed $<3$ neutrophils/10 glomeruli, which was not different from values in four control rats injected with normal sheep IgG. No histologic abnormalities were noted in PHN rats studied up to $5 \mathrm{~d}$.

Five rats injected with specific anti-neutrophil serum had neutrophil counts of $<200 / \mathrm{mm}^{3}$ from before antiFxlA administration until day 4 . Smears from some rats were totally devoid of neutrophils. The value of $<200$ neutrophils $/ \mathrm{mm}^{3}$ frequently represented a single abnormal looking neutrophil in a smear of peripheral blood. On day 5, neutrophil counts exceeded 200 cells/ $\mathrm{mm}^{3}$ in some rats. Therefore protein excretion, measured from days 3-4 rather than days 4-5, was compared to controls. The results of neutrophil counts and urine protein excretion of rats treated with antineutrophil serum and saline-treated controls are shown in Table II. Despite marked neutrophil depletion in the experimental group, there was no difference in urine protein excretion between the groups on days 3-4. In addition, four cyclophosphamide-treated PHN rats that were proteinuric on days $4-5$ (range: $24-50 \mathrm{mg} / 24 \mathrm{~h}$ ) also had neutrophil counts of $<200 / \mathrm{mm}^{3}$ on day 5 .

\section{DISCUSSION}

The results of this study establish that the complement system is an essential mediator of proteinuria in the PHN model of membranous nephropathy in rats. They

TABLE II

Neutrophil Counts and Urine Protein Excretion of PHN Rats Treated with Specific Anti-Neutrophil Globulin or Normal Rabbit Globulin

\begin{tabular}{ccc}
\hline & & Urine protein \\
\cline { 3 - 3 } Group & Neutrophil counts & Days 3-4 \\
\hline $\begin{array}{c}\text { Normal rabbit } \\
\text { globulin }\end{array}$ & $1,100-5,000(6)^{*}$ & $m g / d$ \\
$\begin{array}{c}\text { Anti-neutrophil } \\
\text { globulin }\end{array}$ & $0-200 \quad(5)$ & $34 \pm 9.6 \quad(5 / 5) \S$ \\
\hline
\end{tabular}

* Range of daily neutrophil counts, number studied is in parentheses.

$\ddagger$ Mean \pm SEM, number proteinuric/number studied in parentheses.

$\S$ Not significantly different from control $(P<0.5)$. 
also strongly suggest that this effect is independent of neutrophils and therefore different from previously described mechanisms of complement-induced glomerular injury $(1,4,5,8,16)$. The essential findings can be summarized as follows: Injection of rats with sheep antibody to rat FxlA results in immediate deposition of sheep IgG along the subepithelial surface of the glomerular capillary wall, which increases progressively in amount and granularity over $5 \mathrm{~d}$ in keeping with the kinetics of glomerular antibody deposition in this model defined in previous quantitative studies (18). Within $24 \mathrm{~h}$ rat C3 is detectable by IF deposited in a pattern and intensity similar to that of IgG. Despite this active C3 fixation in vivo, careful sequential studies reveal no neutrophil (or mononuclear cell) infiltrate in glomeruli and no inflammatory histologic changes. After 4-5 d nephritogenic quantities of antibody are deposited along with complement resulting in an increase in glomerular permeability and a marked and nonselective increase in urine protein excretion. Although some host IgG deposition is detectable in glomeruli by IF at the onset of proteinuria, our observations in rats immunosuppressed with cyclophosphamide or lethal irradiation suggest that proteinuria at $5 \mathrm{~d}$ is caused almost entirely by the heterologous antibody.

The critical role of complement in mediating proteinuria in PHN is clearly demonstrated by the finding that C3 depletion with purified CVF prevented glomerular C3 deposition and completely inhibited the development of proteinuria, without reducing the quantity of antibody that deposited in glomeruli or the ability of such deposits to fix complement in vitro. Additional evidence for the complement-dependent nature of glomerular injury in this model was provided by studies using noncomplement-fixing antibodies. We have previously shown that the development of proteinuria on days 4 and 5 in rats given unfractionated anti-FxlA IgG is dependent upon the amount of antibody deposited (18). The threshold of glomerularbound antibody required to produce proteinuria, about $90 \mu \mathrm{g} \mathrm{IgG/2}$ kidneys, was presumably a mixture of $\gamma 2$ (noncomplement-fixing) and $\gamma \mathrm{l}$ (complement-fixing) subclasses (18). From the present study, the proteinuric threshold of glomerular-bound $\gamma 1$ anti-FxlA is clearly $<60 \mu \mathrm{g} \mathrm{IgG/2}$ kidneys, and four of six rats given noncomplement fixing $\gamma 2$ antibodies had more than $60 \mu \mathrm{g}$ IgG in their kidneys at $5 \mathrm{~d}$ but did not become proteinuric. Thus, it is reasonable to conclude that the failure of $\gamma 2$ antibodies to produce proteinuria is due to some property other than the amount of antibody deposited. While supramolar doses of $F\left(a b^{\prime}\right)_{2}$ anti-FxlA antibodies similarly failed to cause proteinuria, we cannot be certain that the amount of $F\left(a b^{\prime}\right)_{2}$ found in glomeruli exceeded the threshold for proteinuria. Coupled with the observation that C3-depletion pre- vented the appearance of proteinuria, it seems likely that the inability of $\gamma 2$ (and perhaps also $F\left(a b^{\prime}\right)_{2}$ ) antiFx1A antibodies to alter glomerular permeability in the doses used is due to their inability to activate complement.

The essential requirement for complement deposition to induce proteinuria in this model was shown to be independent of neutrophils by the complete absence of any detectable neutrophils in glomeruli from the time of antibody injection until after proteinuria developed and by the failure of sustained neutrophil depletion to $<200 / \mathrm{mm}^{3}$ with specific antiserum to significantly alter proteinuria in rats with normal C3 levels. Severe neutropenia was noted also in cyclophosphamide-treated rats in which it similarly failed to prevent proteinuria.

These findings provide convincing evidence that the complement system, from $\mathrm{C} 3$ and perhaps through the terminal components, is an essential mediator of glomerular injury induced by subepithelial immune deposits in PHN. What is unusual, in the light of previous studies of complement-dependent experimental glomerular injury, is the total absence of inflammation during the genesis of the lesion, and the lack of effect of neutrophil depletion. In contrast to our findings in $\mathrm{PHN}$, in nephrotoxic nephritis induced by heterologous anti-GBM antibodies, complement-dependent glomerular injury has been shown, in numerous studies, to be mediated by the action of neutrophils $(4,8,9,15)$, whereas the less common form of noninflammatory glomerular lesion has been shown to be complement independent $(5,10-12)$. Thus, in complement-dependent nephrotoxic nephritis neutrophils are prominent in the glomerulus before the onset of proteinuria $(9,10,15)$ and neutrophil derived proteases, along with GBM fragments, are found in the urine $(4,8,37)$. Neutrophil involvement in complementmediated tissue injury is believed to be effected largely through generation of chemotactic products of complement activation, primarily C5a $(4,8)$. There is no known explanation for the absence of neutrophils from glomeruli despite complement activation in this study, but it might be the result of a barrier to immune adherence provided by the endothelium and GBM that separates the immune deposits from the capillary lumen. The direction of ultrafiltration might also prevent chemotactic factors from reaching the circulation. While neutrophils have recently been shown capable of inducing glomerular damage in the autologous phase of nephrotoxic nephritis without prior complement activation, $(38,39)$, the present study is the first to suggest that the complement system may injure glomeruli without the participation of neutrophils. In the only other study of complement in experimental "immune complex" glomerular disease, complement depletion ameliorated the vasculitis of 
acute serum sickness but had no apparent effect on proteinuria $(4,40)$.

These studies do not elucidate the mechanism of complement-dependent glomerular injury in this model and, since noninflammatory, complement-induced organ damage has not previously been described, any theories of pathogenesis must be speculative. Amelioration of proteinuria in rats depleted of complement or given noncomplement fixing antibodies is clearly not the result of reduced glomerular antibody deposition, which tends to rule out any effect of putative glomerular complement receptors (41) or other factors, such as enhanced reticuloendothelial system clearance of antibody (42) which might have influenced the amount of antibody deposited. Similarly, based on these findings, as well as our previous studies using vasoactive amine blockers in PHN $(18,22)$, it is apparent that immune deposit formation (and consequent proteinuria) is not dependent upon anaphylatoxin (C3a and C5a) or complement-induced vasoactive amine release from mast cells as has been demonstrated in other models (43-45). There is some evidence from tracer studies in Heymann nephritis that electrondense deposits located in the subepithelial space in the region of the slit diaphragm represent areas of increased permeability to macromolecules (46). It is therefore conceivable that alterations in the solubility of immune precipitates during incorporation of complement, as has been described in vitro (47), might give rise to areas of increased permeability resulting in loss of glomerular capillary barrier function.

Finally, it is possible that the terminal C5b-C9 membrane attack complex might, in a way analogous to its cytolytic effect (48), damage the integrity of the glomerular filter. Although there is no evidence that GBM is composed of lipid bilayers, immune deposits in PHN develop in the subepithelial space adjacent to the epithelial cell membrane and membranous slit-pore diaphragm $(17,22)$, which provide the final barrier to filtration of some proteins (49) and might be susceptible to attack by the C5b-C9 complex. Activation of C5b-C9 has been shown to expose hydrophobic peptides which insert into the lipid bilayer of membranes and result in membrane damage (48). This process may result in the release of membrane lipid and some of the inserted peptides are believed to form transmembrane channels that cause osmotic swelling and cell lysis (48). It is of interest in this regard that in complement-dependent nephrotoxic nephritis, an immediate loss of GBM lipid phosphorous occurred after anti-GBM antibody injection that preceded the influx of neutrophils (50), and that less proteinuria occurred in mice deficient in C5 (51).

This study provides new insight into the role of complement in immunologic renal injury and suggests a possible explanation for the noninflammatory nature of certain human glomerular diseases, such as membranous nephropathy and membranoproliferative glomerulonephritis, in which glomerular complement fixation occurs.

\section{ACKNOWLEDGMENTS}

The authors are grateful to Dr. Magda M. Stilmant of the Mallory Institute of Pathology, Boston City Hospital for performing the glomerular neutrophil counts, Dr. Helmut Rennke of the Department of Pathology, Peter Bent Brigham Hospital and Harvard Medical School for the isoelectric focusing studies, Dr. Albert L. Sullivan for cooperation with the radioisotope studies and Dr. Herbert L. Kayne of the Biostatistics Laboratory at the Boston University School of Medicine for statistical advice and assistance in experimental design and data analysis. Neva Capparell and Christine Darby provided expert technical assistance.

Support for this work was provided by research grant AM 17722 and National Research Training Grant AM 07053 (Doctors Salant, Belok, and Madaio) from the United States Public Health Service.

\section{REFERENCES}

1. Wilson, C. B., and F. J. Dixon. 1976. The renal response to immunological injury. In The Kidney. B. M. Brenner and F. C. Rector, Jr., editors. W. B. Saunders Co., Philadelphia. 1st edition. 838-940.

2. Wilson, C. B., and F. J. Dixon. 1979. Renal injury from immune reactions involving antigens in or of the kidney. In Contemporary Issues in Nephrology. C. B. Wilson, B. M. Brenner, and J. H. Stein, editors. Churchill Livingstone Inc., New York. 3: 35-66.

3. Couser, W. G., and D. J. Salant. 1980. In situ immune complex formation and glomerular injury (editorial review). Kidney Int. 17: 1-13.

4. Cochrane, C. G. 1969. Mediation of immunologic glomerular injury. Transplant. Proc. 1: 949-958.

5. Cochrane, C. G. 1979. Mediation systems in neutrophilindependent immunologic injury to the glomerulus. In Contemporary Issues in Nephrology. C. B. Wilson, B. M. Brenner and J. H. Stein, editors. Churchill Livingstone, New York. 3: 106-121.

6. Berger, J., L-H. Noel, and H. Yanerva. 1974. Complement deposition in the kidney. In Advances In Nephrology. J. Hamburger, J. Crosnier and M. H. Maxwell, editors. Year Book Medical Publishers, Inc., Chicago. 4: 37-48.

7. Wyatt, R. J., A. J. McAdams, J. Forristal, J. Snyder, and C. D. West. 1979. Glomerular deposition of complementcontrol proteins in acute and chronic glomerulonephritis. Kidney Int. 16: 505-512.

8. Henson, P. M., and C. G. Cochrane. 1975. The effect of complement depletion on experimental tissue injury. Ann. N. Y. Acad. Sci. 258: 426-440.

9. Cochrane, C. G., E. Unanue, and F. J. Dixon. 1965. A role of polymorphonuclear leukocytes and complement in nephrotoxic nephritis. J. Exp. Med. 122: 99-119.

10. Simpson, I. J., N. Amos, D. J. Evans, N. M. Thompson, and D. K. Peters. 1975. Guinea pig nephrotoxic nephritis. I. The role of complement and polymorphonuclear leukocytes and the effect of antibody subclass and fragments in 
the heterologous phase. Clin. Exp. Immunol. 19: 499-511.

11. Couser, W. G., M. M. Stilmant, and N. B. Jermanovich. 1977. Complement-independent nephrotoxic nephritis in the guinea pig. Kidney Int. 11: 170-180.

12. Hammer, D. K., and F. J. Dixon. 1963. Experimental glomerulonephritis. II. Immunologic events in the pathogenesis of nephrotoxic serum nephritis in the rat. J. Exp. Med. 117: 1019-1034.

13. Unanue, E., and F. J. Dixon. 1964. Experimental glomerulonephritis. IV. Participation of complement in nephrotoxic nephritis. J. Exp. Med. 116: 965-987.

14. Cochrane, C. G., H. J. Müller-Eberhard, and B. S. Aiken. 1970. Depletion of plasma complement in vivo by a protein of cobra venom: Its effect on various immunologic reactions. J. Immunol. 105: 55-69.

15. Henson, P. M. 1972. Pathologic mechanisms in neutrophilmediated injury. Am. J. Pathol. 68: 593-612.

16. Schreiber, R. D., and H. J. Müller-Eberhard. 1979. Complement and renal disease. In Contemporary Issues in Nephrology. C. B. Wilson, B. M. Brenner, and J. H. Stein, editors. Churchill Livingstone Inc., New York. 3: $67-105$.

17. Couser, W. G., D. R. Steinmuller, M. M. Stilmant, D. J. Salant, and L. M. Lowenstein. 1978. Experimental glomerulonephritis in the isolated perfused rat kidney. J. Clin. Invest. 62: 1275-1287.

18. Salant, D. J., C. Darby, and W. G. Couser. 1980. Experimental membranous glomerulonephritis in rats. Quantitative studies of glomerular immune deposit formation in isolated glomeruli and whole animals. J. Clin. Invest. 66: $71-81$.

19. Van Damme, B. J. C., G. J. Fleuren, W. W. Bakker, R. L. Vernier, and Ph. J. Hoedemaeker. 1978. Experimental glomerulonephritis in the rat induced by antibodies directed against tubular antigens. V. Fixed glomerular antigens in the pathogenesis of heterologous immune complex glomerulonephritis. Lab. Invest. 38: 502-510.

20. Couser, W. G., M. M. Stilmant, and C. Darby. 1976 Autologous immune complex nephropathy. I. Sequential study of immune complex deposition, ultrastructural changes, proteinuria and alterations in glomerular sialoprotein. Lab. Invest. 34: 23-30.

21. Rosen, S. 1971. Membranous glomerulonephritis: current status. Hum. Pathol. 2: 209-231.

22. Salant, D. J., S. Belok, M. M. Stilmant, C. Darby, and W. G. Couser. 1979. Determinants of glomerular localization of subepithelial immune deposits. Effects of altered antigen to antibody ratio, steroids, vasoactive amine antagonists and aminonucleoside of puromycin in passive Heymann nephritis in rats. Lab. Invest. 41: 89-99.

23. Mancini, O., A. O. Carbonara, and J. R. Heremans. 1965. Immunochemical quantitation of antigens by single radial immunodiffusion. Immunochemistry. 2: 235-254.

24. Edgington, T. S., R. J. Glassock, and F. J. Dixon. 1968 Autologous immune complex nephritis induced with renal tubular antigen. I. Identification and isolation of the pathogenetic antigen. J. Exp. Med. 127: 555-572.

25. Nisonoff, A., F. L. Wissler, L. N. Lipman, and D. L. Woermley. 1960. Separation of univalent fragments from bivalent rabbit antibody molecules by reduction of disulfide bonds. Arch. Biochem. Biophys. 89: 230-244.

26. Ouchterlony, O. 1970. Handbook of Immunodiffusion and Immunoelectrophoresis. Ann Arbor-Humphrey Science Publishers, Inc., London. 21-31.

27. Ouchterlony, O. 1970. Handbook of Immunodiffusion and
Immunoelectrophoresis. Ann Arbor-Humphrey Science Publishers, Inc., London. 47-57.

28. Rennke, H. G., R. S. Cotran, and M. A. Venkatachalam. 1975. Role of molecular charge in glomerular permeability. Tracer studies with cationized ferritins. J. Cell Biol. 67: 638-646.

29. Rennke, H. G., Y. Patel, and M. A. Venkatachalam. 1978. Glomerular filtration of proteins: clearance of anionic, neutral and cationic horse-radish peroxidase in the rat. Kidney Int. 13: 324-328.

30. Bradley, G. M., and E. S. Benson. 1974. Examination of the urine. In Todd-Sanford Clinical Diagnosis by Laboratory Methods. I. Davidson and J. B. Henry, editors. W. B. Saunders Co., Philadelphia. 15th edition.

31. Mardiney, M. R., and H. J. Müller-Eberhard. 1965. Mouse $\beta$ lc-Globulin: Production of an antiserum and characterization in the complement reaction.J. Immunol. 94: $877-882$.

32. Linscott, W. D., and C. G. Cochrane. 1964. Guinea pig $\beta$ lc-globulin: Its relation to the third component of complement and its alteration following interaction with immune complexes. J. Immunol. 93: 972-984.

33. Couser, W. G., M. M. Stilmant, and E. J. Lewis. 1973. Experimental glomerulonephritis in the guinea pig. I. Glomerular lesions associated with antiglomerular basement membrane antibody deposits. Lab. Invest. 29: 236-243.

34. Shaw, J. O., M. F. Roberts, R. J. Ulevitch, P. Henson, and E. A. Dennis. 1978. Phospholipase $A_{2}$ contamination of cobra venom factor preparations. Am. J. Pathol. 91: $571-578$.

35. Clark, H. F., and N. C. Shepard, 1963. A dialysis technique for preparing fluorescent antibodies. Virology. 20: 642644.

36. Snedecor, G. W., and W. G. Cochrane. 1967. Statistical Methods. The Iowa State University Press, Ames, Iowa. 6th edition.

37. Hawkins, D., and C. G. Cochrane. 1968. Glomerular basement membrane damage in immunological glomerulonephritis. Immunology. 14: 665-681.

38. Thompson, N. M., P. F. Naish, I. J. Simpson, and D. K. Peters. 1976. The role of C3 in the autologous phase of nephrotoxic nephritis. Clin. Exp. Immunol. 24: 464-473.

39. Sindrey, M., and P. Naish. 1979. The mediation of the localization of polymorphonuclear leukocytes in glomeruli during the autologous phase of nephrotoxic nephritis. Clin. Exp. Immunol. 35: 350-355.

40. Henson, P. M., and C. G. Cochrane. 1971. Acute immune complex disease in rabbits. J. Exp. Med. 133: 554-571.

41. Shin, M. L., M. C. Gelfand, R. B. Nagle, J. R. Carlo, I. Green, and M. M. Frank. 1977. Localization of receptors for activated complement on visceral epithelial cells of the human renal glomerulus. J. Immunol. 118: 869873.

42. Bloksma, N., H. Van Dijk, W. Bijlsma, and J. Willers. 1979. Modulation of delayed hypersensitivity in mice by cobra venom factor. Cell. Immunol. 46: 187-191.

43. Fearon, D. T., S. Ruddy, J. D. Knostman, C. B. Carpenter, and K. F. Austen. 1974. The functional significance of complement. In Advances in Nephrology. J. Hamburger, J. Crosnier, and M. G. Maxwell, editors. Year Book Medical Publishers, Inc., Chicago. 4: 15-36.

44. Kniker, W. T., and C. G. Cochrane. 1968. The localization of circulating immune complexes in experimental serum sickness. The role of vasoactive amines and hydrodynamic forces. J. Exp. Med. 127: 119-135. 
45. Henson, P. M., and C. G. Cochrane. 1969. Immunological mediation of increased vascular permeability. II. Two mechanisms of histamine release from rabbit platelets involving complement. J. Exp. Med. 129: 167-184.

46. Schneeberger, E. E., P. D. Leber, M. J. Karnovsky, and R. T. McCluskey. 1974. Altered functional properties of the renal glomerulus in autologous immune complex nephritis. J. Exp. Med. 139: 1283-1302.

47. Takahashi, M., S. Takahashi, V. Brade and V. Nussenzweig. 1978. Requirements for the solubilization of immune aggregates by complement. The role of the classical pathway. J. Clin. Invest. 62: 349-358.

48. Mayer, M. M., C. H. Hammer, D. W. Michaels, and M. L. Shin. 1978. Immunologically mediated membrane dam- age: The mechanism of complement action and the similarity of lymphocyte mediated cytotoxicity. Transplant. Proc. 10: 707-713.

49. Venkatachalam, M. A., M. J. Karnovsky, H. D. Fahimi, and R. S. Cotran. 1970. An ultrastructural study of glomerular permeability using catalase and peroxidase as tracer proteins. J. Exp. Med. 132: 1153-1167.

50. Gang, N. F., W. Mautner, and N. Kalant. 1970. Nephrotoxic serum nephritis. II. Chemical, morphologic and functional correlates of glomerular basement membrane at the onset of proteinuria. Lab. Invest. 23: 150-157.

51. Lindberg, L. H., and L. T. Rosenberg. 1968. Nephrotoxic serum nephritis in mice with a genetic deficiency in complement. J. Immunol. 100: 34-38. 